\title{
A clinical and molecular study of a patient with Simpson-Golabi-Behmel syndrome
}

\begin{abstract}
Simpson-Golabi-Behmel syndrome (SGBS) is one of the overgrowth syndromes. Microdeletions of the glypican-3 (GPC3) gene were described by Pilia et al. (1996). Glypican-3 encodes a putative extracellular proteoglycan which is expressed in embryonic mesodermal tissues and plays an important role in embryonal growth. We report a Japanese patient with SGBS who had a single base deletion in the exon 7 of the GPC3 gene. This is the first report of a single base deletion of the GPC3 gene.
\end{abstract}

Key words Simpson-Golabi-Behmel syndrome · Overgrowth syndrome $\cdot$ Glypican-3 $\cdot$ IGF-2 $\cdot$ Proteoglycan

\section{Introduction}

Simpson-Golabi-Behmel syndrome (SGBS) is one of the overgrowth syndromes. Simpson et al. (1975) reported a new syndrome with the following features: broad stocky appearance, characteristic facies (large protruding jaw, broad nasal bridge, upturned nasal tip), macroglossia, and broad, short hands and fingers. Intelligence was normal. Golabi and Rosen (1984) and Behmel (1984) reported further patients. Garganta and Bodurtha (1992) published a review of the syndrome. Patients often attain a height of

N. Okamoto $(\bowtie)$

Department of Planning and Research, Osaka Medical Center and Research Institute for Maternal and Child Health, 840 Murodo-cho, Izumi, Osaka 594-1101, Japan

Tel. +81-725-56-1220; Fax +81-725-56-5682

e-mail: yb9n-okmt@asahi-net.or.jp

M. Yagi $\cdot$ K. Imura

Department of Pediatric Surgery, Osaka Medical Center and

Research Institute for Maternal and Child Health, Osaka, Japan

Y. Wada

Department of Molecular Medicine, Osaka Medical Center and

Research Institute for Maternal and Child Health, Osaka, Japan more than $195 \mathrm{~cm}$. Xuan et al. (1994) mapped the gene of SGBS to Xq25-q27. Pilia et al. (1996) identified breakpoints in two female patients with X/autosomal translocations. The breakpoints occurred near the glypican-3 gene (GPC3; MIM300037), which spans more than $500 \mathrm{~kb}$ in Xq26. Glypican-3 encodes a putative extracellular proteoglycan which is expressed in embryonic mesodermal tissues and plays an important role during embryonal growth. It is linked to the cell membrane via glycosylphosphatidylinositol. It has putative glycosaminoglycan attachment sites and modulates insulin-like growth factor (IGF)-2 activities. Pilia et al. (1996) reported deletions encompassing exons of the GPC3 gene, and Hughes-Benzie et al. (1996) added other deletions. However, Lindsay et al. (1997) reported that large-scale deletions in the GPC3 gene may account for a minority of cases. We report a patient with SGBS who had a single base deletion in the GPC3 gene.

\section{Case report}

A male neonate was referred to the Pediatric Surgery Department because of congenital diaphragmatic hernia diagnosed by fetal ultrasonography. His birth weight was $3524 \mathrm{~g}$ at 36 weeks gestation $(+2.4 \mathrm{SD})$. The left thoracic cavity was occupied by abdominal organs (Fig. 1). Respiratory care and surgical repair was carried out. SGBS was diagnosed because of somatic overgrowth and the characteristic facial appearance, including hypertelorism, macroglossia, central tongue groove, and high arched palate (Fig. 2). When the infant was 2 months of age, right diaphragmatic hernia was noted and a second operation was done. The bilateral occurrence of diaphragmatic hernia was a unique complication. He had funnel chest and inguinal hernia. At 21 months of age, he showed moderate overgrowth and mild developmental delay. 


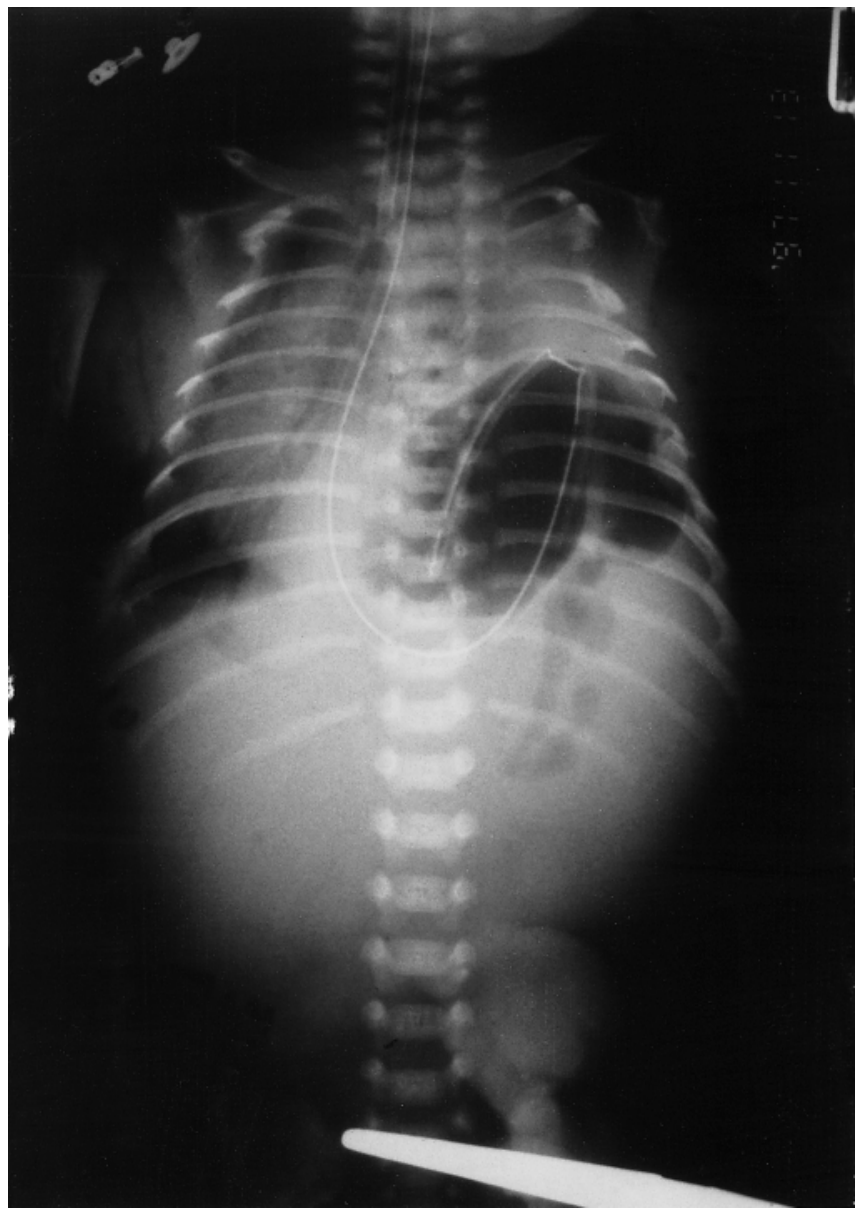

Fig. 1. Roentogenogram showing congenital diaphragmatic hernia

\section{Materials and methods}

DNA from peripheral leukocytes was obtained by standard methods. The exon/intron structures of GPC3 and PCR primer pairs for mutation analysis have been reported by Huber et al. (1997). PCR amplification of each exon was performed, using the primers reported by Pilia et al. (1996) and Huber et al. (1997). Sequence analysis of the PCR products was done by the dye-terminator method (ABI autosequencer model 373A; Perkin-Elmer, Norwalk, CT, USA).

\section{Results}

Large-scale deletion seemed to be less likely, as PCR amplification of each exon was successfully performed (data not shown). Direct sequencing of PCR products was done with the forward primers reported by Huber et al. (1997). One base deletion creating a premature stop codon in exon 7 was found (Fig. 3). Seventy-six C-terminal amino acids, including the putative glycanation site and glycosyl phosphatidylinositol transfer site, were lost. This truncated protein would not be anchored to the cell membrane.

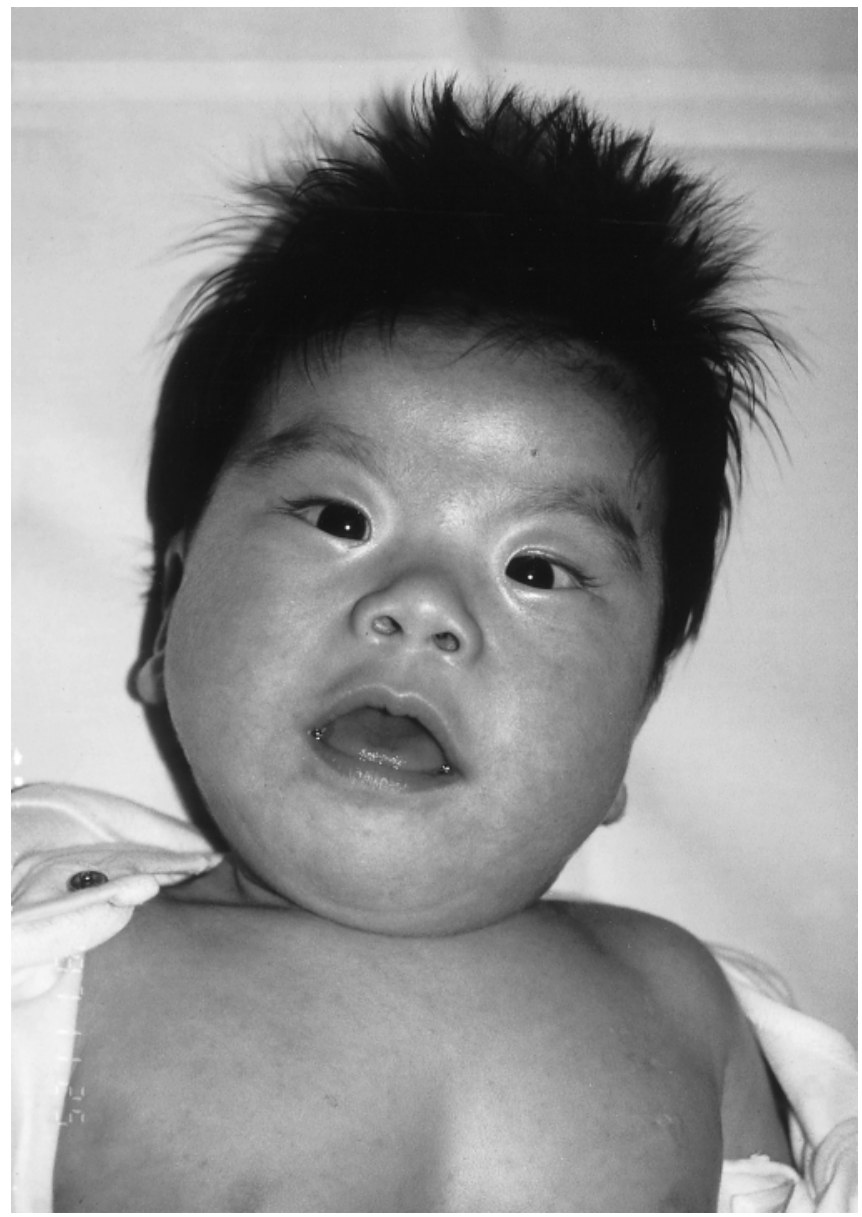

Fig. 2. Facial appearance of the patient, with macroglossia and hypertelorism (Informed consent was obtained for the use of this photograph.)

\section{Discussion}

There has been only one report on SGBS from Japan (Tsukahara et al. 1984). This syndrome is not extremely rare in Japan, as we have encountered three other unrelated patients at our institution during the past 5 years. Patients with SGBS may remain undiagnosed, or they may be misdiagnosed with other overgrowth syndromes, such as Beckwith-Wiedemann syndrome. Perlman syndrome, an autosomal recessive overgrowth syndrome with enlarged dysplastic kidneys, is another differential diagnosis (Verloes et al. 1995). We must consider SGBS in patients with characteristic facial appearance, multiple anomalies, and somatic overgrowth. Chest roentgenogram may be necessary if they have respiratory symptoms. However, diagnosis by this method is sometimes difficult, based on the dysmorphologic aspects only. Molecular analysis of the GPC3 gene may be a useful method for making an accurate diagnosis of SGBS.

Pilia et al. (1996) found GPC3 gene deletions in three of six patients with SGBS, and Hughes-Benzie et al. (1996) reported four further deletions. The mutations in GPC3 were unique deletions, ranging from less than $0.1 \mathrm{~kb}$ to more 
Fig. 3. Sequence analysis of exon 7 of GPC3. Boxed area in the wildtype allele indicates the putative C-terminal glycanation site. One base deletion (1712delC) changed a cysteine residue to a premature stop codon (Cys505stop). The nucleotide number is in accordance with the report by Huber et al. (1997)

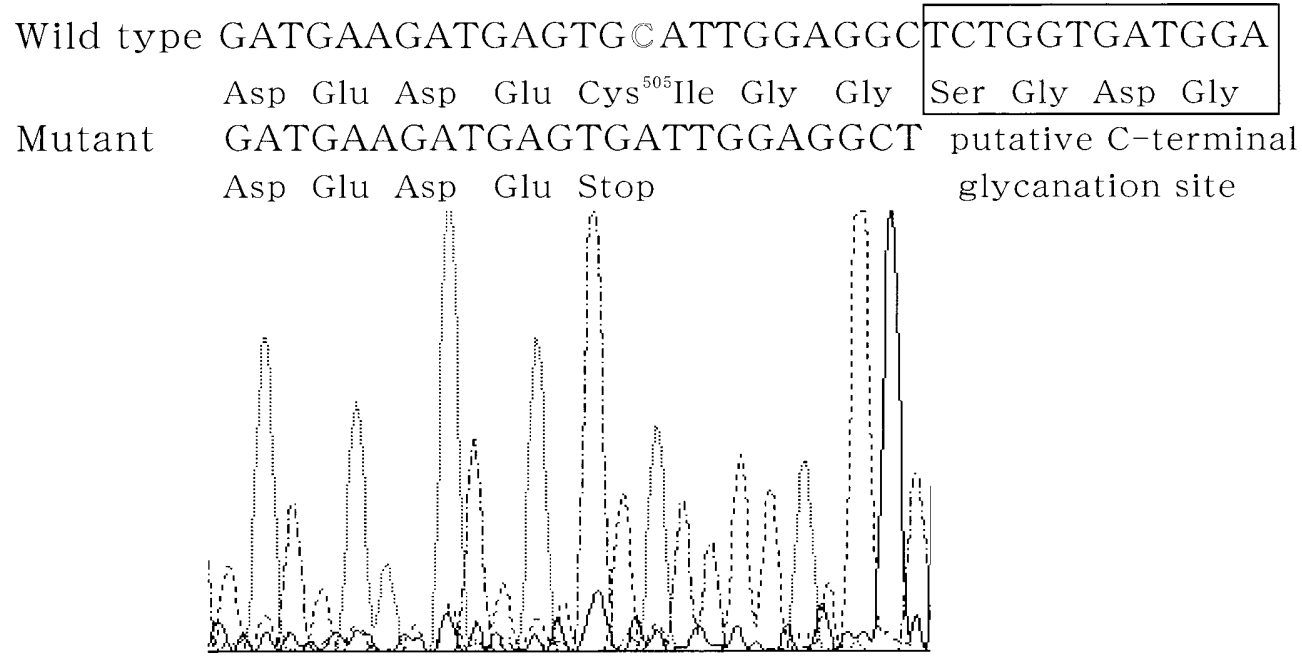

than $300 \mathrm{~kb}$ in length, with no evidence of a mutational hot spot discerned (Pilia et al. 1996). However, Lindsay et al. (1997) found only five deletions in 18 SGBS patients and reported that large-scale deletions in the GPC3 gene may account for a minority of cases. Recently, Xuan et al. (1999) reported a 13-base pair deletion in the GPC3 gene in a Dutch-Canadian SGBS family. They showed that a discrete GPC3 disabling mutation is sufficient to cause SGBS. Our result shows that a single base deletion in the GPC3 gene may be responsible for SGBS, without large-scale deletions.

The mechanism of overgrowth in SGBS is still unknown. Pilia et al. (1996) showed that GPC3 binds IGF-2 and modulates its activities. Overexpression of IGF-2 has been implicated in the pathogenesis of Beckwith-Wiedemann syndrome and in the newly established "IGF-2 overgrowth disorder" (Morison et al. 1996). However, Song et al. (1997) reported that OCI-5, the rat homologue of GPC3, interacts with fibroblast growth factor (FGF)-2, but not with IGF-2. The interaction was mediated by heparan sulfate chains of $O C I-5$. It is possible that GPC3 interacts with other growth factors or proteins that regulate IGF-2 activity.

There is no apparent correlation between the extent of the deletions and the phenotypic expression (Neri et al. 1998). Deletions spanning exons or frame shift mutations are very likely to diminish the function of GPC3 protein. As in our patient, protein lacking the putative $\mathrm{C}$-terminal glycanation site and the glycosyl phosphatidylinositol transfer site is very likely to lose its stability and interaction. Accumulation of other types of mutations will give us further information on the function of GPC3 and its clinical relevance.

\section{References}

Behmel A, Plochl E, Rosenkranz W (1984) A new X-linked dysplasia giantism syndrome: identical with the Simpson dysplasia syndrome? Hum Genet 67: 409-413
Garganta CL, Bodurtha JN (1992) Report of another family with Simpson-Golabi-Behmel syndrome and a review of the literature. Am J Med Genet 44: 129-135

Golabi M, Rosen L (1984) A new X-linked mental retardationovergrowth syndrome. Am J Med Genet 17: 345-358

Huber R, Crisponi L, Mazzarella R, Chen C-N, Su Y, Shizuya H, Chen EY, Cao A, Pilia G (1997) Analysis of exon/intron structure and $400 \mathrm{~kb}$ of genomic sequence surrounding the $5^{\prime}$-promoter and $3^{\prime}$ terminal ends of the human glypican 3 (GPC3) gene. Genomics 45: $48-58$

Hughes-Benzie RM, Pilia G, Xuan JY, Hunter AGW, Chen E, Golabi M, Hurst JA, Kobori J, Marymee K, Pagon RA, Punnett HH, Schelley S, Tolmie JL, Wohlferd MM, Grossman T, Schlessinger D, MacKenzie AE (1996) Simpson-Golabi-Behmel syndrome: genotype/phenotype analysis of 18 affected males from seven unrelated families. Am J Med Genet 66: 227-234

Lindsay S, Ireland M, O'Brien O, Clayton-Smith J, Hurst JA, Mann J, Cole T, Sampson J, Slaney S, Schlessinger D, Burn J, Pilia G (1997) Large scale deletions in the GPC3 gene may account for a minority of cases of Simpson-Golabi-Behmel syndrome. J Med Genet 34: 480-483

Morison IM, Becroft DM, Taniguchi T, Woods CG, Reeve AE (1996) Somatic overgrowth associated with overexpression of insulin-like growth factor II. Nature Med 2: 311-316

Neri G, Gurrieri F, Zanni G, Lin A (1998) Clinical and molecular aspects of the Simpson-Golabi-Behmel syndrome. Am J Med Genet 79: 279-283

Pilia G, Hughes-Benzie RM, MacKenzie A, Baybayan P, Chen EY, Huber R, Neri G, Cao A, Forabosco A, Schlessinger D (1996) Mutations in GPC3, a glypican gene, cause the Simpson-Golabi-Behmel overgrowth syndrome. Nature Genet 12: 241-247

Simpson JL, Landey S, New M, German J (1975) A previously unrecognized X-linked syndrome of dysmorphia. Birth Defects XI: 18-24

Song HH, Shi W, Filmus J (1997) OCI-5/rat glypican-3 binds to fibroblast growth factor-2 but not to insulin-like growth factor-2. J Biol Chem 272: 7574-7577

Tsukahara M, Tanaka S, Kajii T (1984) A Weaver-like syndrome in a Japanese boy. Clin Genet 25: 73-78

Verloes A, Massart B, Dehalleux I, Langhendries J-P, Koulischer L (1995) Clinical overlap of Beckwith-Wiedemann, Perlman and Simpson-Golabi-Behmel syndromes: a diagnostic pitfall. Clin Genet 47: 257-262

Xuan JY, Besner A, Ireland M, Hughes-Benzie RM, MacKenzie AE (1994) Mapping of Simpson-Golabi-Behmel syndrome to Xq25-q27. Hum Mol Genet 3: 133-137

Xuan JY, Hughes-Benzie RM, MacKenzie AE (1999) A small interstitial deletion in the GPC3 gene causes Simpson-Golabi-Behmel syndrome in a Dutch-Canadian family. J Med Genet 36: 57-58 